\title{
ИССЛЕДОВАНИЕ ЦЕЛЕСООБРАЗНОСТИ ИСПОЛЬЗОВАНИЯ ИТАЛЬЯНСКОЙ МУКИ НА РОССИЙСКИХ ПРЕДПРИЯТИЯХ ИНДУСТРИИ ПИТАНИЯ
}

\author{
I.I. Zakharova, E.G. Tolstova
}

\section{THE STUDY OF THE FEASIBILITY OF USING ITALIAN FLOUR AT RUSSIAN ENTERPRISES OF THE FOOD INDUSTRY}

Захарова Ирина Ивановна - ст. преп. кафр. технологии общественного питания Института пищевых технологий и дизайна - фрилиала Нижегородского государственного инженерно-экономического университета, г. Нижний Новгород.

E-mail: irina2727@yandex.ru

Толстова Елена Геннадьевна - ст. преп. каф. товароведения, сервиса и управления качеством Института пищевых технологий и дизайна - филиала Нижегородского государственного инженерно-экономического университета, г. Нижний Новгород. E-mail: eg.tol@mail.ru

В ресторанах итальянской кухни производство пасты все чаще осуществляется из итальянской муки «Semola». Цель работы: исследовать целесообразность применения муки "Semola» для производства пасты. Задачи: изучить пищевую ценность итальянской и российской муки, сравнить их органолептические показатели, приготовить пасту из исследуемых образцов муки, провести ее экспертную органолептическую оценку, выявить влияние стоимости муки на себестоимость блюда и его продажную цену. Для исследования были закуплены следующие образщы: мука из твердой пшеницы для макаронных изделий высший сорт торговой марки «MAKFA» и мука из твердых сортов пшеницы для пасты «Semola per pasta» торговой марки «MOLINO GRASSI». Иcследования проводились в «Кулинарной лаборатории экспериментальных вкусов» Ресурсного иентра Института пищевых технологий и дизайна. Анализ представленных на маркировке муки данных показывает, что отклонения в пищевой иенности итальянской и российской муки весьма незначительны. Проведение органолептического анализа позволяет сделать вывод, что мука "Semola» имеет более желтьй ивет, а ее вкус и запах не имеют никаких существенных отличий от образца российской муки из твердых сортов пшеницы. Из отобран-
Zakharova Irina Ivanovna - Senior Lecturer, Chair of Technology of Public Catering, Institute of Food Technologies and Design - Branch of Nizhny Novgorod State Engineering and Economic University, Nizhny Novgorod.

E-mail: irina2727@yandex.ru

Tolstova Elena Gennadyevna - Senior Lecturer, Chair of Merchandizing, Service and Quality Management, Institute of Food Technologies and Design - Branch of Nizhny Novgorod State Engineering and Economic University, Nizhny Novgorod.

E-mail: eg.tol@mail.ru

ных образцов муки было приготовлено блюдо «Паста с сыром «Пармезан» и проведена органолептическая оценка показателей его качества. Проведение дегустации данного блюда позволяет сделать вывод, что вкусовые качества блюд, приготовленных из разных видов муки, одинаковые. Но блюдо «Паста с сыром «Пармезан» с российской мукой из твердых сортов пшеницы дешевле на 30,15 рубля. Большая стоимость блюд, приготовленных из муки итальянского производства, не оправдана более высокой питательной ценностью или улучшенными вкусовыми качествами пасты для потребителя. Популярность приготовления пасты из итальянской муки обусловлена лишь рекламой итальянских производителей муки.

Ключевые слова: мука из твердых сортов пшеницы, итальянская мука "Semola», пищевая ценность, органолептические показатели качества, потребительские свойства, паста, стоимость готового блюда.

At the restaurants of Italian cuisine the pasta production is more often cooked using Italian Semola flour. The research purpose was to investigate the expediency of application of Semola flour for the pasta production. The tasks were to study nutrition value of Italian and Russian flour, to compare their organoleptic indicators, to cook the pasta 
from studied flour samples, to carry out its expert organoleptic assessment, to reveal the influence of the flour cost on prime cost of the dish and its sale price. For the research the following samples were bought: the flour from durum wheat for the pasta of premium MAKFA trademark and the flour from durum grades of wheat for Semola of the pasta of MOLINO GRASSI trademark. The researches were conducted in "Culinary Laboratory of Experimental Tastes" of the Resource Center of Institute of Food Technologies and Design. Analyzing the data presented at labeling the flour it should be noted that the deviations in nutrition value of Italian and Russian flour are very insignificant. From selected samples of the flour the dish "Pasta with 'Parmesan cheese"' was cooked and organoleptic assessment of its quality indicators was carried out. After tasting this dish one can draw the conclusion that the tastes of the dishes cooked from different types of the flour are identical. But the dish "Pasta with 'Parmesan' cheese" with the Russian flour from durum grades of wheat is 30.15 rubles cheaper. High cost of the dishes cooked from the flour of Italian production is not justified by higher nutritional value or improved pasta tastes for the consumer. The popularity of cooking the pasta from Italian flour is caused only by advertizing of Italian flour producers.

Keywords: durum wheat flour, Italian Semola flour, nutritional value, organoleptic quality indicators, consumer properties, pasta, the cost of finished dish.

Введение. Пшеница и продукты из нее один из богатейших источников различных веществ для человеческого организма. Некоторые аминокислоты, которые содержит этот злак (лизин, триптофран, фенилаланин), являются жизненно необходимыми, так как не синтезируются организмом человека [1].

Мука из твердых сортов пшеницы считается самой полезной. В ней много клейковины и белка, сложных углеводов и жиров. Продукты из твердых пшеничных сортов не способствуют набору веса и не повышают уровень глюкозы в крови. В муке такого типа содержатся незаменимые для человеческого организма минералы - кальций, калий, фоссфор, марганец, натрий и другие. Кроме того, в ней содержатся витамины $B, E, A, P P, C$ [2].

В ресторанах итальянской кухни производство пасты все чаще осуществляется из итальянской муки «Semola». По классификации «Accoциации мукомольной промышленности Италии», «Semola» - мука крупного помола из пшеницы твердых сортов. Она состоит из частиц с острыми краями размером от 200 до 400 микрон [3]. В принципе ее можно считать аналогом российской муки из твердых сортов пшеницы.

Но в последнее время потребители стали более трепетно относиться к местным продуктам, задумываться о том, что, может быть, доставленные из дальних стран товары ничем не отличаются от привычных.

Цель работы. Исследовать целесообразность применения итальянской муки «Semola» для производства пасты.

Задачи: изучить пищевую ценность итальянской и российской муки, сравнить их органолептические показатели, приготовить пасту из исследуемых образцов муки, провести ее экспертную органолептическую оценку, выявить влияние стоимости муки на себестоимость блюда и его продажную цену.

Объекты и методы исследования. В качестве объектов исследования были закуплены следующие образцы:

- мука из твердой пшеницы для макаронных изделий высший сорт торговой марки «MAKFA» массой 1000 г по цене 54 рубля;

- мука из твердых сортов пшеницы для пасты «Semola per pasta» торговой марки «MOLINO GRASSI» массой 1000 г по цене 138 рублей.

В работе применялись общепринятые методы исследования. Образцы муки исследовались на соответствие требованиям ГОСТ 31463-2012 по органолептическим показателям. Рецептура и технология приготовления пасты разрабатывались на основании рекомендаций учебной литературы. Готовая паста оценивалась по органолептическим показателям в соответствии с требованиями ГОСТ 31986-2012.

Результаты и их обсуждение. На потребительской упаковке обоих образцов имеется знак обращения на рынке Таможенного союза, что указывает на безопасность использования данного продукта. Информация для потребителей, предоставленная производителем на упаковке товара, содержит сведения о пищевой ценности отобранных для исследования образцов пшеничной муки. Эти данные представлены в таблице 1.

Анализируя представленные данные, следует отметить, что отклонения в пищевой ценности итальянской и российской муки весьма незначительны. Они никак не могут оправдать более высокую стоимость муки «Semola» и сделать еe использование более предпочтительным. 
Было проведено сравнение по органолептическим показателям отобранных образцов муки пшеничной из твердых сортов пшеницы и итальянской муки «Semola» [4]. Полученные результаты проведенного анализа органолептических показателей качества этих образцов представлены в таблице 2.

\section{Пищевая ценность отобранных образцов муки}

\begin{tabular}{|c|c|}
\hline $\begin{array}{c}\text { Мука из твердых сортов пшеницы } \\
\text { для макаронных изделий высший сорт } \\
\text { торговой марки «MAKFA» }\end{array}$ & $\begin{array}{c}\text { Мука из твердых сортов пшеницы для пасты } \\
\text { «Semola per pasta» торговой марки } \\
\text { «MOLINO GRASSI» }\end{array}$ \\
\hline \multicolumn{4}{|c|}{ Содержание белков } \\
\hline $10,8 \%$ & $11,71 \%$ \\
\hline $1,3 \%$ & $1,08 \%$ \\
\hline $70,0 \%$ & Содержание жира \\
\hline \multicolumn{3}{|c|}{ Содержание углеводов } \\
\hline Содержание пищевых волокон \\
\hline \\
\hline $334 / 1398$ ккал/кДж \\
\hline Энергетическая ценность \\
\hline
\end{tabular}

\section{Органолептические показатели качества образцов муки}

\begin{tabular}{|l|c|c|}
\hline Показатель & $\begin{array}{c}\text { Мука из твердых сортов пшеницы } \\
\text { для макаронных изделий высший сорт } \\
\text { торговой марки «MAKFA» }\end{array}$ & $\begin{array}{c}\text { Мука из твердых сортов пшеницы для } \\
\text { пасты «Semola per pasta» торговой марки } \\
\text { «MOLINO GRASSI» }\end{array}$ \\
\hline Цвет & $\begin{array}{c}\text { Мука имеет светло-кремовый цвет } \\
\text { с легким желтоватым оттенком }\end{array}$ & $\begin{array}{c}\text { Мука имеет четко выраженный светло- } \\
\text { желтый цвет, однородный по всей массе }\end{array}$ \\
\hline Запах & $\begin{array}{c}\text { Мука имеет характерный слабовыражен- } \\
\text { ный запах, не затхлый, не плесневелый }\end{array}$ & $\begin{array}{c}\text { У муки посторонние запахи отсутствуют } \\
\text { Вкус }\end{array}$ \\
$\begin{array}{c}\text { Вкус, свойственный муке из здорового } \\
\text { зерна, без посторонних привкусов }\end{array}$ & $\begin{array}{c}\text { Вкус пресноватый, характерный для } \\
\text { муки, не кислый, не горький }\end{array}$ \\
\hline
\end{tabular}

Проведение органолептического анализа позволяет сделать вывод, что мука «Semola» имеет более желтый цвет, а ее вкус и запах не имеют никаких существенных отличий от образца российской муки из твердых сортов пшеницы.

Из отобранных образцов муки было приготовлено блюдо «Паста с сыром «Пармезан» [5]. Рецептура представлена в таблице 3.

\section{Рецептура блюда «Паста с сыром «Пармезан», г}

\begin{tabular}{|l|c|c|}
\hline \multicolumn{1}{|c|}{ Сырье } & Брутто & Нетто \\
\hline \multicolumn{1}{|c|}{1} & 2 & 3 \\
\hline Мука пшеничная в/с из твердых сортов или мука итальянская «Semola» & 100 & 100 \\
\hline В т.ч. мука на подпыл & 10 & 10 \\
\hline Яйца & 0,9 шт. & 36 \\
\hline
\end{tabular}


Окончание табл. 3

\begin{tabular}{|l|c|c|}
\hline & 2 & 3 \\
\hline Оливковое масло 1 & 2 & 2 \\
\hline Сыр «Пармезан» & 10 & 10 \\
\hline Соль & 1 & 1 \\
\hline Выход лапши & - & 120 \\
\hline Выход & - & 300 \\
\hline
\end{tabular}

Муку просеять, всыпать в чашу миксера. В отдельную емкость освободить яйца от скорлупы, добавить оливковое масло и соль, перемешать. Установить насадку для замешивания теста в виде крюка, вылить яичную массу в чашу с мукой. Замесить тесто на малой скорости.

Готовое тесто завернуть в пленку и убрать в холодильник на 30-40 минут для дозревания (набухания клейковины). Шар теста раскатать в колбаску длиной $30 \mathrm{~cm}$, затем разрезать его на 10 кусочков и сложить в функциональную емкость, закрыть влажной тканью.

Установить насадку для раскатки теста. Брать по одному кусочку, раскатать в лепешку. Немного посыпав муки на пласты теста, нарезать их, свернуть аккуратно, чтобы паста не слиплась.
Варить пасту в большом количестве подсоленной воды до консистенции «альденте (Al dente)» (этот термин обозначает полностью приготовленную пасту, которая тем не менее по-прежнему слегка твердая, что придает ей привлекательную текстуру) около 2-3 минут, помешивая деревянной ложкой. На каждые 100 г пасты необходим примерно 1 литр воды для варки.

Готовую пасту откинуть на дуршлаг, а затем переложить в посуду, добавив немного бульона, оставшегося от варки, для сочности. Сверху посыпать сыром «Пармезан».

Была проведена органолептическая оценка показателей качества пасты, приготовленной из различных видов муки [6]. Полученные данные представлены в таблице 4.

\section{Органолептические показатели готового блюда}

Таблица 4

\begin{tabular}{|l|l|l|}
\hline $\begin{array}{c}\text { Показатель } \\
\text { качества }\end{array}$ & \multicolumn{1}{|c|}{$\begin{array}{c}\text { Паста с сыром «Пармезан», } \\
\text { мукой «Semola» }\end{array}$} & \multicolumn{1}{|c|}{$\begin{array}{c}\text { Паста с сыром «Пармезан», } \\
\text { мукой из твердых сортов пшеницы }\end{array}$} \\
\hline Внешний вид & $\begin{array}{l}\text { Паста в виде длинной лапши, одинако- } \\
\text { вая по размерам, выложена в круглые } \\
\text { тарелки d=32 см, посыпана тертым сы- } \\
\text { ром }\end{array}$ & $\begin{array}{l}\text { Паста в виде длинной лапши, одинако- } \\
\text { вая по размерам, выложена в круглые } \\
\text { тарелки d=32 см, посыпана тертым сы- } \\
\text { ром }\end{array}$ \\
\hline Цвет & Однотонный с желтоватым оттенком & $\begin{array}{l}\text { Однотонный, с более насыщенным } \\
\text { желтым оттенком }\end{array}$ \\
\hline Вкус & $\begin{array}{l}\text { Свойственный виду изделия, в меру со- } \\
\text { леный, без посторонних привкусов, сыра }\end{array}$ & $\begin{array}{l}\text { Свойственный виду изделия, в меру со- } \\
\text { леный, без посторонних привкусов, сыра }\end{array}$ \\
\hline Запах & Без посторонних запахов & Без посторонних запахов \\
\hline Консистенция & $\begin{array}{l}\text { Однородная, без следов непромеса, } \\
\text { «альденто (Аl dеnте)» }\end{array}$ & $\begin{array}{l}\text { Однородная, без следов непромеса, } \\
\text { «альденто (Аl dente)» }\end{array}$ \\
\hline
\end{tabular}

Паста, приготовленная из муки «Semola», имеет более желтоватый цвет. Все остальные органолептические показатели идентичны.

В процедуре дегустации готовых блюд в качестве экспертов принимали участие 4 преподавателя профрессиональных модулей, работающие в ИПТД. Оценка качества проводилась по 5-балльной шкале. Полученные результаты представлены в таблице 5 .

Проведение дегустации блюда «Паста с сыром «Пармезан» позволяет сделать вывод, что вкусовые качества блюд, приготовленных из разных видов муки, одинаковые. 


\section{Результаты дегустационной оценки}

\begin{tabular}{|c|c|c|c|c|c|c|}
\hline $\begin{array}{c}\text { Показатель } \\
\text { качества }\end{array}$ & $\begin{array}{c}\text { Эксперт } \\
\text { № } 1\end{array}$ & $\begin{array}{c}\text { Эксперт } \\
\text { № } 2\end{array}$ & $\begin{array}{c}\text { Эксперт } \\
\text { № } 3\end{array}$ & $\begin{array}{c}\text { Эксперт } \\
\text { № } 4\end{array}$ & $\begin{array}{c}\text { Ср. } \\
\text { значение }\end{array}$ & Итого \\
\hline \multicolumn{7}{|c|}{ Паста с сыром «Пармезан», мукой «Semola» } \\
\hline Внешний вид & 5 & 5 & 5 & 5 & 5 & \multirow[t]{5}{*}{4,9} \\
\hline Цвет & 4 & 5 & 5 & 5 & 4,75 & \\
\hline Вкус & 5 & 5 & 5 & 5 & 5 & \\
\hline Запах & 5 & 5 & 5 & 5 & 5 & \\
\hline Консистенция & 5 & 5 & 4 & 5 & 4,75 & \\
\hline \multicolumn{7}{|c|}{ Паста с сыром «Пармезан», мукой из твердых сортов пшеницы } \\
\hline Внешний вид & 5 & 5 & 5 & 5 & 5 & \multirow[t]{5}{*}{4,9} \\
\hline Цвет & 5 & 5 & 5 & 4 & 4,75 & \\
\hline Вкус & 5 & 5 & 5 & 5 & 5 & \\
\hline Запах & 5 & 5 & 5 & 5 & 5 & \\
\hline Консистенция & 5 & 4 & 5 & 5 & 4,75 & \\
\hline
\end{tabular}

Был произведен расчет себестоимости и продажной цены блюда «Паста с сыром «Пармезан», мукой «Semola» и блюда «Паста с сыром «Пармезан», мукой из твердых сортов пшеницы. Расчет производился согласно приведенной выше рецеп- туре. Для этого составлены калькуляционные карты (форма № ОП-1), расчет производился на основании стоимости сырья на сто блюд для наиболее точного определения цены одного блюда. Данные представлены в таблице 6.

\section{Калькуляция на блюдо «Паста с сыром «Пармезан»}

Таблица 6

\begin{tabular}{|c|c|c|c|c|c|c|}
\hline \multirow{2}{*}{$\begin{array}{c}\text { Порядковый номер } \\
\text { калькуляции, продукты }\end{array}$} & \multicolumn{3}{|c|}{$\begin{array}{c}\text { Блюдо № } 1 \\
\text { «Паста с сыром «Пармезан», } \\
\text { мукой из твердых сортов пшеницы }\end{array}$} & \multicolumn{3}{|c|}{$\begin{array}{c}\text { Блюдо № } 2 \\
\text { «Паста с сыром «Пармезан», } \\
\text { мукой «Semola» }\end{array}$} \\
\hline & $\begin{array}{c}\text { Hopma, } \\
\text { кг }\end{array}$ & $\begin{array}{l}\text { Цена, } \\
\text { руб. }\end{array}$ & $\begin{array}{l}\text { Сумма, } \\
\text { руб. }\end{array}$ & $\begin{array}{l}\text { Норма, } \\
\text { кг }\end{array}$ & $\begin{array}{l}\text { Цена, } \\
\text { руб. }\end{array}$ & $\begin{array}{l}\text { Сумма, } \\
\text { руб. }\end{array}$ \\
\hline 1 & 2 & 3 & 4 & 5 & 6 & 7 \\
\hline $\begin{array}{l}\text { 1. Мука пшеничная в/с } \\
\text { из твердых сортов }\end{array}$ & 9,0 & 54,00 & 486,00 & - & - & - \\
\hline 2. Мука итальянская «Semola» & - & - & - & 9,0 & 138,0 & 1242,00 \\
\hline 3. Яйца & 90 шт & 6,00 & 540,00 & 90 шт & 6,00 & 540,00 \\
\hline 4. Оливковое масло & 0,2 & 350,00 & 70,00 & 0,2 & 350,00 & 70,00 \\
\hline 5. Сыр «Пармезан» & 1,0 & 900,00 & 900,00 & 1,0 & 900,00 & 900,00 \\
\hline 6. Соль & 0,1 & 9,00 & 0,90 & 0,1 & 9,00 & 0,90 \\
\hline $\begin{array}{l}\text { Общая стоимость сырьевого на- } \\
\text { бора на } 100 \text { блюд }\end{array}$ & - & - & 1996,9 & - & - & 2752,9 \\
\hline Наценка 300 \%, руб. & \multicolumn{3}{|c|}{5999,7} & \multicolumn{3}{|c|}{8258,7} \\
\hline Цена продажи блюда, руб. & \multicolumn{3}{|c|}{79,97} & \multicolumn{3}{|c|}{110,12} \\
\hline $\begin{array}{l}\text { Выход одного блюда в готовом } \\
\text { виде, грамм }\end{array}$ & \multicolumn{3}{|c|}{300} & \multicolumn{3}{|c|}{300} \\
\hline
\end{tabular}


Приобретая блюдо «Паста с сыром «Пармезан» С мукой из твердых сортов пшеницы в предприятиях индустрии питания, где наценка на блюдо составляет $300 \%$ и более, потребитель может заплатить за него 79,97 рублей. Продажная цена такого же блюда, изготовленного с итальянской мукой "Semola», составит 110,12 рубля. Представленный расчет однозначно демонстрирует, что блюдо «Паста с сыром «Пармезан», российской мукой из твердых сортов пшеницы дешевле на 30,15 рубля.

Выводы. Проведенное исследование позволяет сделать итоговый вывод: мука из твердых сортов пшеницы для макаронных изделий высшего сорта торговой марки «MAКFA» российского производства ничем не уступает муке из твердых сортов пшеницы для пасты «Semola per pasta» торговой марки «MOLINO GRASSI» по следующим показателям: пищевая ценность; органолептические показатели качества; потребительские свойства при приготовлении такого популярного блюда, как паста.

Поэтому большая стоимость блюд, приготовленных из муки итальянского производства, не оправдана более высокой питательной ценностью или улучшенными вкусовыми качествами пасты для потребителя.

Популярность приготовления пасты из итальянской муки обусловлена лишь рекламой итальянских производителей муки, стремящихся расширить рынок сбыта своего продукта и получить дополнительную прибыль.

\section{Литература}

1. Товароведение однородных групп продовольственных товаров: учеб. для бакалавров / Л.Г. Елисеева, Т.Г. Родина, А.В. Рыжакова [и др.]; под ред. Л.Г. Елисеевой. М.: Дашков и К ${ }^{\circ}, 2015 .-930$ с.

2. Нилова Л.П. Товароведение и экспертиза зерномучных товаров: учебник. - СПб.: ГИОРД, 2005. - $416 \mathrm{c}$.
3. Синельников С.М., Соломоник Т.Г., Лазерсон И.И. Кухня Италии. - М.: Центрполиграфр: ООО «МиМ-Дельта», 2004. - 702 с.

4. ГОСТ 31463-2012. Мука из твердой пшеницы для макаронных изделий. Технические условия. - М., 2012.

5. Технология продукции общественного питания / А.С. Ратушный, Б.А. Баранов [и др.]. - М.: Дашков и Кㅇ, 2016. - URL: http://www.biblioclub.ru/- Университетская библиотека «ONLINE».

6. ГОСТ 31986-2012. Услуги общественного питания. Метод органолептической оценки качества продукции общественного питания. Издание официальное. - М.: Стандартинформ, 2014. - 11 с. ,

\section{Literatura}

1. Tovarovedenie odnorodnyh grupp prodovol'stvennyh tovarov: ucheb. dlya bakalavrov I L.G. Eliseeva, T.G. Rodina, A.V. Ryzhakova [i dr.]; pod red. L.G. Eliseevoj. - M.: Dashkov i $\mathrm{K}^{\circ}, 2015 .-930 \mathrm{~s}$.

2. Nilova L.P. Tovarovedenie i ekspertiza zernomuchnyh tovarov: uchebnik. - SPb.: GIORD, 2005. - $416 \mathrm{~s}$.

3. Sinel'nikov S.M., Solomonik T.G., Lazerson I.I. Kuhnya Italii. - M.: Centrpoligraf: 000 «MiMDel'ta», 2004. - $702 \mathrm{~s}$.

4. GOST 31463-2012. Muka iz tverdoj pshenicy dlya makaronnyh izdelij. Tekhnicheskie usloviya. - M., 2012.

5. Tekhnologiya produkcii obshchestvennogo pitaniya / A.S. Ratushnyj, B.A. Baranov [i dr.]. - M.: Dashkov i $\mathrm{K}^{\circ}, 2016$. - URL: http://www.biblioclub.ru/- Universitetskaya biblioteka «ONLINE».

6. GOST 31986-2012. Uslugi obshchestvennogo pitaniya. Metod organolepticheskoj ocenki kachestva produkcii obshchestvennogo pitaniya. Izdanie oficial'noe. - M.: Standartinform, 2014. - $11 \mathrm{~s}$. 